\title{
Negative Images in Contemporary Art: Aesthetic Interpretations
}

\author{
Oleg Krivtsun ${ }^{1, *}$
}

${ }^{1}$ State Institute for Art Studies, Moscow, Russia

*Corresponding author. Email: Oleg_Krivtsun@mail.ru

\begin{abstract}
The article touches upon the forms of implementation of negative images in contemporary art. The increase in the proportion of negative images in painting is associated with artistic reaction to controversial processes in modern culture, with the reflection of existential crisis. According to the author, the new understanding of individuality and its needs, the complications of the quest for the life purpose lead to a sharp modification in painting styles, the expansion in the variety of painful topics and focal points which used to be outside the realm of art. Nonetheless, the nature of creation itself can "propel" the artist to perceive the situation in an unconscious-intuitive way, to gain control over it, to make the spectator feel empathy, even if the author's ratio is affected by distortive reflection.
\end{abstract}

\section{Keywords: art, creation, negative images, nonclassical art, artistic dimensions, evolution of needs}

\section{INTRODUCTION}

Rarely do most audiences nowadays take a liking to contemporary art, that is, to the art of the 20th and the 21 st centuries. It is more often that they are wary of it: they look hard at it, compare it with other works, they feel dubious, they reject it. At first sight, indeed, contemporary painting practices have almost nothing in common with the painting in its heyday: the art of the 17th and the18th centuries, the times of Rembrandt, Velázquez, Rubens, Goya, Poussin. The first thing that strikes one's eye is that the proportion of negative images in art has evidently grown in the last one hundred and fifty years.

No doubt, in the past, too, we often come across images telling the story of the "world past praying for", monstrous, terrifying images - in the works of Hieronymus Bosch, Pieter Bruegel, Francisco Goya. The artists-explorers of the post-Renaissance never confined their art to romantic, serene and peaceful images. The audacious brush of every prominent artist is full of sarcastic freethinking - that is source of Bosch's eschatology, Bruegel's doubts about the existence of solid foundations in the world, Goya's eerie images.

Contemporary artists feel that they are exploring various spheres of life even to a greater extent - using intuition, their own instinct, artistic taste and serendipity rather than ratio.

Why does the art of the last one hundred and fifty years pay special attention to the "nocturnal consciousness"? Contemporary artists realize that their life unfolds in the whole different world view and take much effort to make their works able to represent the age in an artistic way, to express the controversial spirit of the age. The proven and adapted means of classical art turn out to be useless in the artistic implementation of dramatic and tragic collisions that modern people face.

\section{NEGATIVE IMAGES AND THE FEATURES OF THE LANGUAGE OF NONCLASSICAL ART}

To begin with, we need to answer the following question: what do we define as negative images in art? Are they negative from the daily, moral point of view, or are they negative from the aesthetic perspective? How can Art Studies today interpret the poignant, painful, depressive images created by Egon Schiele, René Magritte, Francis Bacon, Anselm Kiefer, JeanMichel Basquiat? Their works demonstrate the state of painful sensuality, loneliness, existential dead end, anthropologic catastrophe almost. And nevertheless, all the above mentioned creators have a very strong style. Most art critics will admit that. The works of these 20th century artists are beyond any expected, ordinary "format", yet they are full of vitality. It turns out that painters do not lose their nerve when they solve the problem of "art and evil" nowadays. So impressive is their work that art can contend with life in any of its forms. If the perception of such works does not evoke catharsis ("purification through fear and compassion for the tragic action"), then such perception is full of sympathy, empathy, engagement in the creation. And this is enough for us to talk about full-fledged artistic relationship between the author and the spectator. 
Returning to the subject of classical painters, it is necessary to admit that for all the radiant hopes and promises of the Enlightenment, it proved to be a failure. It turned out that reliance on science as the ultimate expression of human's rational faculty does not make people happy, does not solve global problems and does not eliminate most human vices. Centuries go by, and yet bribery and corruption prevail over high and low spheres of society, one may achieve social success not through their professional skills but through being loyal. Within this topic, it is necessary to understand that all the above mentioned things are not the characteristics of some abstract society, but largely are the qualities of humans themselves. These qualities are nothing but efficient means of survival and rivalry which recur from generation to generation - the way humans understand and feel them, although most often they try not to discuss that.

It is worth mentioning that a century before that, before the "nonclassical" age, there were voices undermining the gracious ideas about human nature. A prominent figure among them was Bernard Mandeville (1670-1733), the author of the sensational "Fable of the Bees". He claimed: "What makes man a social animal is neither his sociability nor good nature, compassionateness, friendliness, nor other amiable, attractive qualities. The most essential characteristics, which help man adjust to the life in the biggest, happiest, most prosperous societies, are his vilest and most disgusting qualities."

The author developed several themes in his fable, and they sharply contradicted Renaissance beliefs: "What we call the world's evil, both moral and physical, is the great principle which makes us social beings, it is a solid basis, a life-giving force which supports all occupations and activities without any exception; and in that very moment when the evil stopped existing, the society would sink into degradation, if not collapse totally" [1]. To those who wanted to revive "the golden age", Mandeville sarcastically advised to be ready in that case not only to become honest, but also to feed on acorns.

Mandeville's harsh ideas were an attempt to fight the inertness of thought which bred clichés like "human nature is neither good nor bad from birth, it is subject to improvement", etc. It was a bold action in its own way - to evaluate human essence impartially through the complex relations between the biological and the social which determine the content of real actions. Mandeville paid particular attention to the role of the civilization which often creates the conditions which make humans adventurous, make them change roles, make them ready to give up their beliefs or have none.

Mandeville was criticised for the fact that both spoke about the "marginal" sides of the human character and emphasised that they were universal, permanent human traits. One can implicitly guess from the fable that Mandeville tried to explain the process of exploration in art at that time when negative characters and heroes were common.

Reflecting on the "nocturnal consciousness" phenomenon, one cannot avoid mentioning a very important idea from Hegel's works. The great thinker argued that the evil played a far greater role in the world history than the good. Hegel did not mean that most people are mercenary, malevolent and full of vice. However, he meant that political intrigues, adventurousness of the capitalist entrepreneurship, ignoble traits of human character catalysed sociocultural changes more often than human rightmindedness.

\section{EMERGENCE OF NEW ARTISTIC DIMENSIONS IN CULTURE}

How important was all that happened for art? Disillusion in people? Understanding of the true power of their instincts, the role of irrational affects in their destiny?

A lot of work had been carried out during the postRenaissance centuries to form a comprehensive enough dictionary of the art theory. Such defining artistic criteria as the beautiful, degree, harmony, integrity, form have become fundamental notions. Real artistic practice, altered intellectual atmosphere, starting from the middle of the 19th century revealed that the situation was utterly different. One of the most significant features of nonclassical aesthetics was marginalisation of the notion of the beautiful. From that moment on the beautiful is perceived not as the ultimate purpose of art, but as one of its possibilities. The notions of beauty and art become more and more distant from each other, and new ideas about art become associated with the notions of "expressive", "entertaining", "convincing", "original", "interesting" ("cool" if we use modern slang). Such new tendencies in art and its theory were inspired by the idea of art free from panlogism which did not level the paradoxicality of the real world, but which had the ability to take all its irrational features in. Recklessly implement the poignancy and complexity of "non-Euclidean geometry", see oneself and the world as space of flexion which is hard to understand. So did, for instance, the impressionists - Édouard Manet, Edgar Degas, Auguste Renoir, Claude Monet and others, who convincingly proclaimed validity of subjectivity and relativity of human perception and who made colour, light, air and form autonomous parts of their language.

The same could be said about the so-called "nonclassical music" which blurred and even denied the principles of classical harmony and cultivated unfamiliar intervals, discordance, atonal music, 
incarnating (according to conservative contemporaries) "neuroticism", rejecting the principles of melody, often basing the entire work on sophisticated rhythmical principles, sound strokes outside melodic basis. In this respect, the works of Richard Strauss, Arnold Schoenberg, Igor Stravinsky, Alban Berg, Dmitri Shostakovich, Sergei Prokofiev, Paul Hindemith, Ernst Křenek, Olivier Messiaen, Benjamin Britten and others are symptomatic.

The same could be said about painting. Such fundamental academic notion as "colour tolerance" becomes an obsolete notion in art theory. New painters audaciously combine intense colours: brown and blue, bright green and red, and so on. This practice is characteristic of such major movement of the 20th century as expressionism, which emerged in the very beginning of the 20th century and which has retained its aesthetics up to present day.

Old textbooks will tell us about expressionism emerging as a painful reaction to the atrocities of civilization of the beginning of the 20th century, World War I and revolutionary movements. However, such explanation is superficial and oversimplistic, it is recording the image outside its complex expression. Of course, its first authors represent a generation traumatised by the slaughtering of the world war. Nonetheless, in their works, they did not convey what they had seen, but presented a new type of artistic consciousness which in an unusual way expressed the new world and the new man who replaced classic forms.

Expressionism of the 20th century is manifested in various artistic forms including painting, literature, theatre, architecture, music, dancing and cinema. The prevalence of negative images per se does not say anything about the power and influence of this artistic movement. Franz Marc, Emil Nolde, Ernst Kirchner, Max Pechstein, Otto Mueller developed their own expressive devices. By means of rough, twisted lines, fast, heavy strokes, glaring hues and sharp colours, the artists expressed the state of anxiety, spiraling elation, indignation and horror.

The expressionist movement (in particular, the art of painters close to the artistic group "Die Brücke", founded in 1905) demonstrates colossal energy which cannot be explained only by thoroughly describing the devices they use. The thing is that, on the one hand, the expressionists brought the role of colour to the level of being worth for its own sake. Probably, such exuberant use of striking shades - ruddy, fiery-red, deep blue, violet means trouble; all these colours as if radiate anxiety, these are really physical properties which bear impulses of excitement and even irritation. On the other hand, in some fantastic way, the physical effect of colour, without ceasing to be one, becomes symbolic at the same time. And then, what seems like gloomy, heavy mood in the portrait at first sight, is being perceived as contemplative, retrospective. Canted composition, lop-sided figures, ultimate condensation (often by means of big, impasto strokes) and crystallisation of elements - air, water, storm, leady clouds - reveals some distinctive "Cezannism" of the expressionists.

Their style reveals the way they reduce central and background images to trapezoid forms, cones and squares. All of these creative findings visually concretise energy: when impressionists evince light breeze and fresh sea air, expressionists demonstrate a storm or a hidden force which is ready to explode. One can hear thick, almost deafening power of organ in their works, the seeming unsteadiness of atmospheric phenomena is modified into their firmness, authoritativeness - either of the world mind, or the greatness of a man who is able to remain standing in the proposed modalities. Certainly, the masters of the movement have both self-irony and perplexity, however, the most important thing about their works is the colossal will to live. We see a high artistic type of entelecheia, which allowed the painters, without giving up their sincerity, spurt their state of mind from the world of absurdity into the world of "non-absurdity". To demonstrate great spiritual strength, "independence" of their models, landscapes, still-lives as the fundamental meaning of their works.

These semantic accents, regardless of the wellknown art history formulas about the "soreness" and "mental brokenness" of the expressionists - out of convincing original conceptual programmes, out of conventional artistic symbolism - strike a chord in the spectators' hearts. Interestingly, while contemplating about the effective secrets of this type of art, one cannot dare to use such elevated and fragile concept as "aura" to evaluate it. It is more likely that we are exposed to powerful energy, empathy, direct emotional blow which induces deep attachment and sympathy to the artist from those who remained standing after this blow. By developing and modifying the aesthetics of expressionist styles such prominent painters as Wassily Kandinsky, Henri Matisse, Max Beckmann, Oskar Kokoschka, Marianne von Werefkin, Alexej von Jawlensky and many others who are now considered classical, won their fame.

It is necessary to understand that all the changes in the mindset of the painters, poets and composers on the cusp of the 19th and 20th centuries were provoked both from the outside (by a set of cultural ideas in philosophy, science, practice) and from the inside: newest artistic movements, each in their own way, were changing the age they had emerged in. 


\section{THE NEED TO PERCEIVE NEGATIVE IMAGES}

A special problem which arises when one seeks to understand the relationships between art and morality is related to comprehension of the reasons why affective sides of human mind, extreme human impulses, which often lead to severe consequences and even catastrophes, are attractive for art. It is evident that elements of "nocturnal consciousness" which are revealed through extreme situations in works of art, live in every one of us to some extent. Negative, controversial material which attracts art is a richer life than the one we experience firsthand. In many ways such artistic focus meets the inner needs of our mind as well. International and national psychologists have used various materials to come to the conclusion, again and again, that the instinct for exploration, for the pursuit of new things that lives inside every person can even go beyond the instinct of self-preservation. The need to go beyond the frames of the rationally familiar, to take risks, to obey the inner element can push aside the safety instinct. On the one hand, no doubt, every organism strives for balance and adaptation, on the other - balance taken to the extreme can lead to stagnation. It is then that one feels the urge to violate adaptability, the urge to relate oneself to a more complex and unusual situation.

The need to exceed oneself implies increasing complexity of skills, acquisition of multidimensional possibilities. External conditions may be advantageous to the greatest possible extent, not sending alarming impulses, however, a person can "with no particular reason" abandon comfort and set out for a voyage across the Atlantic, climb the mountains, although it entails great risk to life. Philosophers and psychologists wrote on multiple occasions about this need as being deeply natural, essential "human eccentricity", the need to go beyond the boundaries given to the subject [2]. It is the endless space in the inner world of humans that make them human, make them stand out from all the other world. In philosophical anthropology such distinction is related to "eccentric" (according to Helmuth Plessner) position of the inner person in relation to the external self.

The urge to break the uniformity of life, expand the horizons of the ordinary leads to the experience of what is beyond the norm. A famous film theorist S. Kracauer once said that the success of a film in many ways depends on the goodness and brightness of the villain playing in it. A good villain means a good film; "it is the person you like to hate".

Is it possible to claim that such attitudes of the audience indicate that there are some vicious qualities of the human nature that are exploited by art? Herman, the protagonist of "The Queen of Spades", an opera by P.I. Tchaikovsky, sings: "I may stare at you and stare in hatred, But my eyes can never feast their fill!" A. S. Pushkin himself wrote: "All, all that threatens to destroy fills mortal hearts with secret joy beyond our power to explain". It is evident that this refers to those magnetic states which aesthetics can interpret as gloomy elevation and which are attractive in their own way. Moreover, obsession with indefinable metaphysics, the ineffable, the vaguely anticipated is a deep essential part of artistic creativity.

According to an acknowledged researcher of artistic needs J.G. Cawelti, the average person seeks confirmation of familiar norms, relations and notions in their perception of new works. They appreciate escapist works which help to get away from reality without making efforts to decipher unfamiliar symbolism and lexis. In arthouse, artistic implementation is always unpredictable, it lacks conventionality inherent to the "formular world", it requires retention and combination of many associations in one's memory, sensitivity to subtle nuances. As a result of perception arthouse works of painting, literature, theatrical works, many problems may remain unsolved, become the source of new uncertainty and anxiety for a person. Mass audience wants to "cover" the unfamiliar. The average person will never agree to admit the existence of controversial, unadapted qualities of mind that new works open up in their conscious and the unconscious. A connoisseur, in contrast, wants to uncover the unfamiliar and is not afraid to admit that the whole spectrum truly exists inside of them.

From such perspectives one can relate to a rather harsh quote by wise Thomas Mann who contemplated a lot on the subject: "Who shall unriddle the puzzle of the artist nature? Who understands that mingling of discipline and licence in which it stands so deeply rooted? Our magisterial style is all folly and pretence, our honourable repute a farce, the crowd's belief in us is merely laughable. And to teach youth, or the populace, by means of art is a dangerous practice and ought to be forbidden. For what good can an artist be as a teacher, when from his birth up he is headed direct for the pit?" [3] Indeed, in the hearth of creativity, discipline and licence are mingled. Passion and culture. Instinct and a sense of form. The painter does not stick to what they have once found. They want to go beyond open horizons. Yes, the pit lures them in. Most people live to hide the pit, Nothingness, from themselves, being satisfied by the seeming security and safety. The horror of emptiness sleeps in ordinary life. Yet only through experiencing this horror we come to understand our mortality, impermanence, shiftiness of all forms of concern for the individual which are dictated by the civilization. We come to understand our own ability to be, regardless of the bitterness of new truths.

There is no need to disguise that: the new art with its images and expressive devices turns out to be rather 
problematic, "uncomfortable" to be used for direct educational purposes which require distinctness and unambiguity. To understand the intentions, radiated by a complex artistic object, adequately, and to evaluate them correctly, a person should be well-versed in reading artistic mediations.

What does a person look for in the terrifying, in the dangerous, in the incredible abyss? Perhaps it is the human "dark sides" that seek release of negative emotions? This explanation should not be disregarded. To a great extent, by means of art people can eradicate passions and vice. Art in that case serves as a mirror in which people see their imperfection. One can put their beliefs and illusions to the test through artistic experience. Moving into artistic reality, one can touch the hidden merciless chaos which is ready to destroy any given destiny. Feeling the coolness from the abyss, one, nonetheless, still experiences the feeling of security and the feeling of being far from the abyss at the moment of artistic perception. The uniqueness of artistic experience-satisfaction is manifested through the fact that, on the one hand, a person is in the situation, and on the other hand - they are outside of it. This mechanism in many ways defines the nature of artistic catharsis.

Thus, negative (in ethical sense) material plays an important role in art. One way or another, through affected experiences, one gets acquainted with the most diverse, controversial aspects of being, one obtains their self-identity and gets socialized. The reader and the spectator sift through, choose feelings and relations that are the most adequate for their inner world. And they become convinced at the same time that their own imagination has dark sides and vices in a "recorded state".

There is one more explanation of the art paying attention to the affected, to the extra. By dealing with dense, concentrated expression of great human passions, art can reveal some essential parts of being, which slip away from us in our everyday existence. What comes as incredible, sharp, knocking down in art can reveal hidden aspects of life, the "secrets of being". In relation to this, J. Maritain considered it legitimate to say about special artistic morality which prompts the artist to have morally risky practices. "An artist wants to try every fruit of the earth, drink from all of its vessels and be completely educated in terms of evil to feed their art in their turn" [4]. Curiosity of this kind is the driving force which makes the artist take any risk and face the hardships coming in their way and in the way of others. The philosopher believed that it was the poetic experience of an outworldly artist, the experience full of various abnormalities, that drives them to aesthetic virtue in the end. Virtue in itself is not able to dictate the right choice to the artist.
In this relation, I will note that we have been and still are overestimating social factors, which feed art to some extent. It is necessary to admit that possible personal pessimistic moods of the author going through existential crisis are one thing, and his natural talent for creation in any social conditions is another thing.

I will refer to a common opinion about the art of Francis Bacon (1909-1992). Most people point out the depressive impression in the works of the English artist who consistently, from painting to painting, includes human images distorted by animal grimaces and convulsions. The world's horror wails from his paintings with toothy mouths and ragged animal bodies, it is manifested in the twisted plasticity of the human body. If Munch displays protest, pain for the human, then Bacon expresses statement done with an incredible nerve of a surgeon. The English painter is a man with no illusions. And, nonetheless, this spontaneous existentialist always used art as a stoic resistance to the horror of existence, the absurdity of reality and the aggression of social actuality. (In brackets, I will note that perhaps the artist intuitively understood that the painterly skill to establish a diagnosis already makes one master of the situation!) Bacon himself shrewdly noted that "the plot should not cry louder than colours".

Francis Bacon is terrifying, catastrophical - and yet one wants to revisit his works. Is not it the criterion of authenticity of a work - the hypnotic desire to return to it again? Bacon sends a sharp message to the world, records the signs of destruction and self-destruction, the signs of apocalypse. However, if a painter lifts their hand before the canvas and incarnates the wounds of individual and cultural Being - then it is possible to claim that the painter is not their own voice anymore, but the voice of the Universe. Creating his own style, Bacon can establish a diagnosis as a creator. And this is not that little. That is, the creator does not give up they paint, and, as we and they believe, is in control of the situation, they perceive themselves if not as a master, then as a contemplator and a participant in what is going on. They provide reference points which should be perceived and that people want to reflect upon. I believe that this statement is valid for similar trends in modern music, theatre and literature.

Many people will be surprised to hear what Francis Bacon said himself: "I think that art is obsession with life, and since we are people, after all, our biggest obsession is ourselves" [5]. The thoughts of a prominent modern master Damien Hirst, who is now in the prime of life, are also interesting: "Life and death are in everything, aren't they?... People say: your art is about death". And you simply answer: "No, it's about life." Even if we take semantic level: rather, death means not doing art. But it is impossible to make art truly negative because the process itself is positive" [6]. 
The painter found the strength to lift their hand before the canvas in spite of everything. Is not it a manifestation of the need to catch some new essence of life? In this case the spectator feels that the painter is has the same way of thinking as they do, they are their contemporary who, despite their fatality, gazes into life again and again. Can we regard this fatality, expressed by means of artistic language, although through a spectrum of negative images, as a victory?

\section{CONCLUSION}

Despite the permeation of negative material into the imagery of modern art and sharp experiments to transform the artistic form, art studies continue to search for such dimensions that could be viewed as distinctive features of artistry and could help to perceive new modern criteria of art quality. As it was already mentioned, to evaluate the greatness of modern works of art, one cannot always use the classical notion of catharsis. Perhaps, the effect of deep empathy with the works of nonclassical art that spectators experience, the high concentration of inner energy at the moment of perception may be more precisely defined by the notion of vitality of art that is larger than the notion of catharsis.

Throughout the centuries, the notion of vitality of art has been commensurate to the notion of "high life", to the feeling of elevation at the moment of artistic experience, and has been regarded as the requirement for obtaining new life energy. Today, high amplitude of artistic dramatism embodying "cry and wail of strangled flesh" (Th. Adorno), contravention, the sharply tragic, the doomed, demands the search for new dimensions - what does painful art give to a person? Perhaps a comprehensive interpretation of the notion of vitality of art, new contemplation about the motives of art and the nature of its indirectness can help to answer the question: why is such art that demonstrates fatality, compression, perishability important to people? That is, the art that newspaper critics often tend to classify as "antihumanist".

Thus, "Determinate Being" and "abandonment in the world", the role of "fear", "anxiety", the experience of one's own mortality causing deep deformations to the reflecting mind - all of these are factors that do not weight down the role and purpose of art, but serve as the given natural environment for it to exist in today.

\section{References}

[1] B. Mandeville, "The Fable of the Bees", 1974, p. 45.

[2] H. Plessner, "The Levels of the Organic and Man: Introduction to Philosophical Anthropology", 1928, pp. 31-58.

[3] Th. Mann, "Collected works in ten volumes", 1966, vol. 10, p. 214.
[4] J. Maritain, "The Responsibility of the Artist" in: "SelfConsciousness of European Culture of the 20th Century", 1991, p. 191.

[5] Cit. ex: V. Mikhailov, "Realism, actually. The School of London in Moscow" in: "The Art Newspaper Russia", 2019, no. 71, p. 58.

[6] Cit. ex: A. Cole, Interview with Damien Hirst, "Colour is a Good Opportunity to Avoid Darkness" in: "The Art Newspaper Russia", 2019, no. 74, p. 34. 